\title{
Propiedad, contrato y poder
}

\section{Javier Iguíñiz Echeverría ${ }^{1}$}

Estamos observando en los últimos años un proceso de reafirmación de los derechos de propiedad privada y de aumento en la importancia del contrato entre particulares dentro de las relaciones económicas. En lo fundamental, dicho proceso no es nuevo. Ese movimiento buscó independencia respecto del 'Estado absoluto' para poder crear empresas y acumular riqueza. La argumentación reciente en favor de ese orden económico basado en el mercado se ha apoyado en los debates del período mercantilista (siglo XVII-XVIII) y, en el debate reciente sobre la naturaleza de la informalidad, en la utilización de supuestas similitudes entre el proceso latinoamericano y peruano de las décadas pasadas y el que se registró al inicio de la revolución industrial. La argumentación en contra se ha basado en doctrinas socialistas del siglo XIX que contraponía lo individual a lo colectivo y lo privado a lo público. Hoy, ambas contraposiciones son materia de sospecha y existe la percepción de que ambas polaridades falsean gravemente la realidad y de que el triunfo de los proyectos de progreso basados en el predominio de uno de los dos términos de cualquiera de las polaridades deja sin resolver problemas importantes de la convivencia humana.

1 Profesor Principal del Departamento de Economía de la Pontificia Universidad Católica del Perú (PUCP). Investigador del Instituto Bartolomé de las Casas - Rímac. El autor agradece los comentarios del profesor Antonio Peña de la Facultad de Derecho de la PUCP, quien leyó una versión previa y parcial. Los errores en materia jurídica que queden son producto de mi terquedad. Este artículo es una versión ampliada de "Dominio sobre las cosas, imperio sobre las personas: propiedad, contrato y poder", publicada en la revista Páginas. Vol. XXIII, No. 149. Lima: Centro de Estudios y Publicaciones febrero 1998. 
En la primera parte trataremos de la distinción público-privado desde una mirada jurídica y también desde la de algunos grandes economistas. ${ }^{2}$ No analizaremos en esta oportunidad la distinción individualcolectivo.

En la segunda, vamos a mostrar el significado que la teoría económica actual le ha dado a la propiedad privada, a las relaciones contractuales y a la libertad que emana de ella. Lo haremos presentando el caso de la relación de esclavitud a la que recientemente se está recurriendo a menudo en los textos de economía.

En la tercera parte sacaremos algunas de las consecuencias políticas de la valoración del contrato; entre ellas, el nuevo (en realidad la reafirmación del antiguo) rol del Estado y de la ley tras la crisis de los Estados de bienestar y socialistas.

En la conclusión resumiremos nuestras inquietudes e impresiones sobre el orden social que parecería estarse instaurando tras las reformas institucionales de los últimos años.

\section{Propiedad y poder (soberanía)}

En esta parte vamos a concentrarnos en el cuestionamiento la separación público-privado para mostrar que lo que está en juego con la distribución de la propiedad es más que un asunto económico o de riqueza-pobreza; es también uno de poder, de soberanía. Además pretendemos recordar que la polémica no debe ser entre lo público y lo privado pues hay mucho de público en lo privado y viceversa.

La relación contractual es una relación de poderes, otorga y rescinde soberanías; ese el planteamiento central que recogemos de un eminente jurista norteamericano Morris Cohen y que citamos a menudo en lo que sigue. Contra la tradicional división en el mundo de las leyes entre el derecho privado que se preocupa de la propiedad y del contrato y el derecho público que se concentra en asuntos políticos, incluyendo

2 Nos estamos refiriendo a la separación de campos entre política y economía. "La visión de Montesquieu de que las leyes políticas de ninguna manera deben cercenar la propiedad privada porque ningún bien público es mayor que el mantenimiento de la propiedad privada fue recogido por Blackstone y se convirtió en la base del pensamiento legal en los EE.UU. de Norteamérica." Cohen 1927, 155. 
obviamente el asunto de la soberanía, la realidad es que, como indicó dicho autor en $1927^{3}$, ambos aspectos de las relaciones entre personas están bastante más juntos de lo que se cree. ${ }^{4}$ De hecho, los contratos son asunciones y cesiones de soberanía. Esta relación es tan estrecha que se llega a afirmar que la propiedad es soberanía.

\section{a. Propiedad y soberanía}

Para entender el significado de este aspecto de las relaciones entre las personas conviene recordar varias distinciones conceptuales. Una de ellas tiene que ver con el origen de la distinción entre propiedad y soberanía. "La distinción entre propiedad y soberanía es generalmente identificada con la discriminación romana entre dominium, el poder del individuo sobre las cosas, e imperium, el poder del príncipe sobre los individuos." ${ }^{5}$ En la Edad media estas dos relaciones estaban muy conectadas. "La esencia de la ley feudal... es la conexión inseparable entre la propiedad de la tierra y el homenaje (homage) personal que a menudo incluía labor como sirviente de parte del arrendatario y siempre una auténtica soberanía del terrateniente sobre el arrendatario." El planteamiento de este autor es que la distinción privado-público propia del derecho oculta las conexiones que no desaparecen con la edad media entre propiedad y poder.

La segunda distinción está relacionada a la anterior y es la que separa el significado de 'propiedad' como cosa del significado de ese término como relación entre personas. Hablar de "mi propiedad" alude a ciertas cosas poseídas por mí. Pero las relaciones de propiedad son siempre relaciones entre propietarios. La esencia del derecho de propiedad privada es el derecho a excluir a otros de ciertas cosas. ${ }^{7}$ En el mundo

3 Ponemos de relieve la fecha para mostrar que los debates fundamentales están basados en cambios más antiguos y más importantes que los que se pretenden hoy por el neoliberalismo. En dicho año el jurista hizo la presentación en la Facultad de Leyes de Cornell. Con pequeños cambios fue publicada en Cornell Law Quarterly, vol. XIII (1927). Luego se publicó como parte del libro que se cita en las referencias.

4 La ventaja de citar a Cohen no es solo la derivada de basarnos en un clásico en el tema sino que nos permite mostrar que el debate de fondo no es con las expresiones más recientes de anti-estatismo neoliberal. El proceso es más antiguo, accidentado y profundo y depende del crecimiento del tamaño de las empresas privadas y de la cada vez más indefinida frontera entre lo privado y lo público.

5 Cohen 1927,156

6 Cohen, ibid.

7 La teoría económica convencional ha partido siempre de una situación en la que el 
liberal, poseerlas no se relaciona con la responsabilidad de compartirlas y sí se identifica con el derecho a excluir a otros del acceso a ellas y a sus beneficios. La ley no asegura las habilidades para un uso adecuado de dichas cosas, simplemente garantiza el poder de excluir a otros del uso y beneficios de las cosas bajo mi propiedad. Lo importante en nuestro tema es que en la medida en que esas cosas que yo poseo sean necesarias para que el otro viva, su posesión, refrendada por la fuerza de la ley o de la simple fuerza particular, me da un cierto poder sobre el otro. Uno de los efectos posibles de ese poder, uno muy utilizado en la historia de la humanidad, es poder exigirle que haga algo que me interesa, que me sirva. Esa necesidad ajena puede ser directa o de bienes finales (alimentos) o indirecta o de bienes intermedios o herramientas y equipos.

En la sociedad moderna ese poder del propietario sobre los excluidos del bien apropiado no es siempre menor al que tenía el amo respecto de los esclavos o el patrón respecto de los siervos. Por ejemplo, el margen de maniobra para administrar su tiempo de trabajo que tenía el esclavo o el siervo respecto de su amo puede ser mayor que el que tiene un asalariado. ${ }^{8}$ La propiedad, pues, confiere al propietario un poder soberano que se expresa en su capacidad de exigir servicio en su beneficio y obediencia del otro. Eso está en la esencia de todo contrato de trabajo. Para usar la terminología del derecho romano: el dominio sobre cosas es a la vez un imperio sobre personas.

Estamos así ante una aproximación a la propiedad que determina más que la capacidad de imponer precios como en el caso de los monopolios la naturaleza de las relaciones entre las personas, el tipo de relación entre ellas en aspectos fundamentales.

\section{b. La inspiración clásica y la actualidad}

En el mundo moderno, la relación entre propiedad y poder ha sido clara desde el principio. Desde Locke la justificación de un Estado

excluido había desaparecido del escenario. El problema económico ha sido el de la asignación de las cosas ya apropiadas con reglas que prescinden toralmente de la presencia del excluido. En ese sentido, decir que el homo economicus es egoísta es absurdo; no hay en la teoría respecto de quién serlo. No existe otro interés que el propio. Por eso, la teoría económica de los derechos de propiedad es de muy reciente aparición.

8 Barzel, 1989. 
limitado estaba, como ahora en el Perú, asociada a la defensa de una propiedad privada ilimitada. Que este tipo de propiedad era excluyente resultaba obvio para los grandes pensadores del tema. De ahí, la estrecha asociación entre la propiedad y su distribución por un lado y la necesidad de una autoridad política por otro. "El gobierno civil, en cuanto instituido para asegurar la propiedad, se estableció realmente para defender al rico del pobre, o a quienes tienen alguna propiedad contra los que no tienen ninguna." $\mathrm{El}$ derecho a la propiedad privada ha sido desde sus inicios el derecho de los propietarios.

Así la institución política estaba directamente conectada con el mundo de las relaciones privadas entre propietarios y entre éstos y los no propietarios. Esta asociación suponía la autoridad de unos y la subordinación de otros. La mera propiedad sobre las cosas o instrumentos necesarios para vivir no era suficiente como para ejercer el poder que de ella se derivaba. Hacía falta el Estado, pero no debía inmiscuirse en las relaciones socio-económicas y de poder privado que se establecían entre las partes. De ahí se deriva que el tema de la propiedad pase a ser un asunto privado mientras que el del Estado y su rol sea materia del derecho público.

El Estado, inicialmente al menos, no sólo no eliminó la relación privada de poder que se establecía entre propietarios y no propietarios con la concentración de propiedad sino que orientó el problema del poder hacia la esfera pública dejando libres a los privados. Unos libres para contratar y despedir y otros libres sólo para despedirse. Todos ganaron algo de libertad pero la insatisfacción de las necesidades básicas constituía el acicate para asegurar que quien sólo era libre para despedirse no lo hiciera nunca definitivamente. ${ }^{10}$ El poder y la subordinación privados se 'balancearon' u ocultaron con el acercamiento de las personas al poder en otra esfera, la pública, en la que el súbdito pasaba a ser ciudadano, mientras en la privada seguía de súbdito. Mientras la subordinación en lo privado aumentaba con la concentración de los medios de producción en manos de unos pocos el Estado se retiraba de la regulación de dicha relación.

9 Smith, 1958, 633. Como veremos más adelante, la nueva teoría de los derechos de propiedad no acepta el planteamiento de que hay gente que no tiene ninguna propiedad. Hasta el esclavo será visto como propietario.

10 En la experiencia de colonización norteamericana eso sí podía ocurrir. 
Sólo después, como consecuencia del aprovechamiento máximo de las relaciones de poder propias del mundo privado por los empresarios y de la respuesta sindical ante la miseria y el maltrato que ello suponía que el Estado interviene en ese mundo del poder privado. El rol tuitivo del Estado en las negociaciones entre capitalistas y asalariados, la naturaleza tripartita de la negociación, es expresión de esa injerencia pública en lo privado. Además, los propios sindicatos, asociados a partidos laboristas, socialistas, comunistas y socialcristianos buscaron un lugar en el escenario público para forzar la presencia del Estado en la desigual relación entre privados. Consiguieron como ciudadanos lo que no podían lograr como súbditos dentro del ámbito privado.

Pero esta línea de asociación poder-Estado y de separación entre esa esfera y la privada siguió su camino tras la crisis económica del "Estado de bienestar" en los años 70 del siglo XX. Un aspecto de la presente desestatización, como veremos adelante, es el de privatizar las relaciones contractuales y hacer del poder privado un poder efectivo reduciendo la intervención pública sobre la base del interés común. El poder privado, derivado directamente de la propiedad de capital y de la posibilidad de sacarlo del ámbito en el que el Estado tiene injerencia puede ejercerse así más plenamente. El libre movimiento de capitales es un factor clave para determinar si hace falta el Estado para hacer respetar el derecho de propiedad. El Estado mismo cambia de ubicación y es menos importante, o por lo menos, también él más subordinado. Pero acabemos este acápite con dos referencias más sobre la relación propiedad-subordinación. Nada menos que los dos fundadores del clasicismo y del neoclasicismo respectivamente lo introdujeron en sus análisis explícitamente.

Para Adam Smith, nuevamente inspirador, esta vez del neoliberalismo, las cosas eran claras. Hacía falta poder público y la ${ }^{*}$ creación de una subordinación distinta, en cierto sentido adicional a la propia del mundo privado. Después se mostraría que era más fácil reducir esa subordinación por medio de la conquista de la ciudadanía que reducir la propia del ámbito económico privado. Así nos parece que se puede ver el planteamiento de Smith en una perspectiva más larga. "El gobierno civil supone una cierta subordinación; pero como su necesidad crece gradualmente con la adquisición de propiedad valiosa, las principales causas que de una manera natural introducen la subordinación, crecen parejamente con el incremento de esa propie- 
dad." 11 En efecto, parece que cuanto mayor fuera la propiedad, mayor era el dominio de los propietarios sobre los que no lo son, pero también era mayor la respuesta de estos últimos contra las consecuencias de dicha concentración.

El Estado se hacía más necesario. No hubiera sido así, si la concentración de propiedad hubiera resultado en relaciones sociales nuevas que les parecieran convenientes a los propios subordinados. Las relaciones de poder en este caso ideal ocurrirían sin necesidad del Estado, serían exclusivamente privadas. Pero la historia no ha sido así, el positivismo, el socialismo, el comunismo y el socialcristianismo de diferentes maneras y con diversos motivos cuestionaron la situación en el mundo privado bajo el nombre por ejemplo de la "cuestión social". Saber cuánto ha influido el hecho de que la concentración de propiedad se hizo expropiando a los no propietarios de su tierra, cuánto el trato que los propietarios dieron a los que no lo eran y tenían que subordinarse o cuánto a otros factores no es nuestra tarea ahora.

La inquietud por la relación propiedad-subordinación estaba también presente en los neoclásicos. Como indicó León Walras «... el modo de apropiación depende de nuestras decisiones, y según que estas decisiones estén bien o mal tomadas, el modo de apropiación será bueno o malo. Si bueno, coordinará los destinos de las personas entre sí, satisfará la justicia; si malo, subordinará el destino de unas personas al de otras, habrá consagrado la injusticia.» ${ }^{12}$ Estirando algo su argumento, parece sugerir el autor que si la propiedad fuera adecuadamente distribuida, al no haber injusticia, dicha propiedad coordinaría los destinos de todos y, podemos inferir, quizá no haría falta el Estado o tanta necesidad de una instancia pública que asegurara el derecho de los propietarios. A fin de cuentas, tradicionalmente, el problema de la justicia se sitúa en el ámbito de lo público mientras que la ética lo hace en el privado. León Walras, el economista que probablemente ha contribuido más a sustentar el supuesto de las "armonías universales» en el mercado estaba muy claro respecto de la importancia de una adecuada decisión en torno a la estructura de la propiedad.

11 Smith, 1958, 629. Resulta muy interesante leer en las páginas que siguen las cuarro causas de la subordinación humana en este pensador. Ellas son: las cualidades personales, la edad, la fortuna y el nacimiento. No está demás recordar que Smith trata de este tema en el capítulo sobre los "gastos de la justicia."

12 Walras, $1978,170$. 
El neoliberalismo trata de volver el reloj hacia atrás en el campo de las relaciones privadas. El problema es que la época social-demócrata, socialista, etc., ha dejado huella en buena medida irreversible y resulta imposible erradicar la existencia de factores definitivos, como por ejemplo, de una ética cívica, de ciudadanos y no de súbditos que ha echado raíces en los países con más trayectoria sindical y democrática y que obliga al mundo empresarial a reflexionar a toda velocidad sobre su nuevo status en la sociedad y en su imperiosa necesidad de ganar legitimidad. ${ }^{13}$ Por supuesto, no pocos empresarios están aprovechando del espacio abierto por la marginación del Estado en el ámbito privado para estirar jornadas de trabajo, reducir la calidad de los ambientes laborales, etc., lo que Marx llamaba el aumento del plusvalor absoluto, esto es, de la agudización de la explotación con la pobreza. No es ese el camino que las grandes empresas en los campos de punta tecnológica consideran viable, ni competitiva ni moralmente. El debate está abierto y es de gran trascendencia en el mundo desarrollado. ${ }^{14}$

\section{c. Una ilustración de gobierno: la sobrevivencia de los súbditos}

Si propiedad y poder van especialmente juntos en ciertas esferas de la vida, es natural que se genere un conflicto por el poder. Un ejemplo, sobre un asunto que incita pasiones en el mundo neoliberal, y en sus críticos puede aclarar esto. Una decisión de la Corte Suprema de los EE.UU. de Norte América en la que no se condenó el pago de salarios inferiores a un mínimo vital motiva que Cohen indique que "con tal decisión los intereses monetarios privados reciben precedencia sobre la responsabilidad soberana del Estado de mantener niveles de vida decentes." ${ }^{15}$ De ese modo, se le quita al Estado el derecho a prohibir pagos que sean infrahumanos desde el punto de vista de los requerimientos de la familia para vivir. La libertad de contratar se convierte en un derecho equivalente al de propiedad, en una libertad sobre la que nadie, y menos el Estado, tiene poder, "en un estiramiento del signifi-

13 Cortina, 1994, cap. 2.

14 Por ejemplo, en EE.UU. de Norteamérica hay diversas opciones de avance económico y social en tensión. Piore 1995. El debate entre el enfoque europeo y el de los EE.UU. es otro ejemplo de gran trascendencia y el relativo a la relación entre desarrollo y derechos humanos entre occidente y oriente también.

15 Cohen, 1927, 157. 
cado del término 'propiedad' hasta incluir lo que nunca antes había significado en la ley o la jurisprudencia de ningún país civilizado."

Nuestro punto central es, pues, que la propiedad es muchas veces poder sobre otras personas al punto de excluir a las otras de la posibilidad de obtener de manera independiente su subsistencia. Excluir a otros de ciertos bienes equivale a excluirlos de esa independencia y de la libertad que supone. La consecuencia es el establecimiento de relaciones de soberanía de unos, que deben ser servidos, sobre otros que están forzados a ofrecer sus servicios. Pero, como hemos anotado en el párrafo anterior, la prestación de un servicio, puede no ser suficiente para vivir y eso siempre ha sido responsabilidad del soberano. Podía no cumplirla pero de ser así caía en falta; era obvio que tenía que cuidar de la vida de sus súbditos concediéndoles tierras en arrendamiento y protegiéndolos de los enemigos. Ambos aspectos iban juntos a tal punto que la concesión de medios de vida era la condición para que luego la propiedad fuera protegida con la fuerza de las armas empuñadas por los súbditos. Hoy, la protección del soberano se concentra cada vez más en la defensa ante ciertos ataques, que no son otros que los que definen a su ejecutor como delincuente, pero no incluye la garantía de la subsistencia. ${ }^{17}$ De ahí la emergencia de esa novísima faceta de la vida humana: el desamparo económico. El neoliberalismo busca separar lo más posible estos dos componentes de la responsabilidad soberana $y$, encima, responder al Estado de bienestar y al socialismo reduciendo en la mayor medida posible la asunción por el Estado de la responsabilidad por la subsistencia de los ciudadanos.

\section{d. Propietario: soberano}

La amplitud de la soberanía que el sector privado reclama a costa de la del Estado es mayor de la que él mismo imagina. La ley y los aparatos

16 El jurista añade más adelante algo que es parte de la actual argumentación neoliberal. "Puede ser que las fuerzas económicas corregirán ellas mismas el abuso que la Corte Suprema no permite al Estado eliminar directamente, que las fuerzas económicas eliminarán las empresas parasitarias que no pagan el mínimo de subsistencia porque tales empresas no son tan económicamente eficientes y rentables como las que si pueden pagar mayores salarios. Igualmente se argumentó que la esclavitud iba a desaparecer debido a su ineficiencia económica." Cohen, 1927, 158.

17 Véase al respecto: Iguíñiz,1993. 
organizados del Estado que respaldan el derecho de propiedad privada protegen no sólo el derecho al uso de las cosas apropiadas; también protegen los ingresos que se puedan derivar de ellas. Este es, de hecho, el derecho principal en el mundo de hoy; el relativo a los beneficios económicos de la propiedad de un activo. La propiedad privada de la tierra le da derecho al terrateniente a recaudar una renta, la propiedad de una compañía de teléfonos de la da al dueño el derecho a cobrar por el servicio telefónico de hoy y de mañana, y la propiedad de un bono del Estado le da a uno derecho a una parte de la recaudación tributaria futura.

"Desde este punto de vista puede ser rápidamente entendido que cuando una corte de justicia determina que una compañía de gas tiene el derecho a un retorno de $6 \%$ sobre su inversión no está solamente protegiendo propiedad ya poseída, también está determinando que una porción del producto social futuro deberá ir bajo ciertas condiciones a dicha compañía. De ese modo, no sólo los señores medievales sino también todos los propietarios de activos que proveen renta están autorizados por ley a cierto poder de recabar impuestos sobre el futuro producto social. Cuando a este poder tributario se le añade el poder de mandar a muchos que no son económicamente independientes y ponerlos a su servicio tenemos la esencia de lo que históricamente ha constituido la soberanía política." 18

Cuando aplicamos este criterio ya no a empresas pequeñas que mandan a pocos y que reciben una parte pequeña del producto social en razón exclusivamente de su propiedad, sino a grandes empresas, muchas de ellas mayores que la mayor parte de los países del mundo

18 Podría parecer extraño que Cohen $(1927,160)$ llame 'impuesto' a la renta obtenida por los propietarios. El intento de asociar dicho ingreso con el trabajo no tiene validez desde los orígenes de la teoría económica moderna. Como indicó Adam Smith: "Habrá acaso quien se imagine que estos beneficios del capital son tan solo un nombre distinto por los salarios de una especie particular de trabajo, como el de inspección y dirección. Pero son cosa completamente distinta, regulándose por principios de una naturaleza especial, que no guardan proporción con la cantidad, el esfuerzo o la destreza de esta supuesta labor de inspección y dirección. Los beneficios se regulan enteramente por el valor del capital empleado y son mayores o menores en proporción a su cuantía." (Smith, 1958, 48) 
estamos ante una soberanía política que compite con la de los Estados. Esa competencia no es sólo debida a la soberanía sobre otros que proviene de la propiedad privada, cualquiera que sea la escala de operaciones, sino también al gran tamaño de la propiedad privada.

\section{e. ¿Soberanía sobre el Estado nacional?}

El argumento anterior, salvo en el último párrafo, se refería a la relación entre personas o entre personas y organizaciones o entre empresas; sin embargo, no nos parece totalmente impropio incluir en él a los países. Si la propiedad otorga un poder de contenido político, es obvio que en el caso del capital financiero e industrial, su libertad para irse de una región determinada o de una nación hace de la entidad política regional o nacional en cierto sentido dependiente del propietario privado. Aunque no se debe aplicar de manera exacta el argumento anterior podemos aventurar que el Estado, en la medida en que se autoexcluya o sea forzado a excluirse de la propiedad de los medios de producción tiene que sostenerse y cumplir sus funciones recurriendo a quienes sean los propietarios. La estatización de hace varias décadas y la privatización reciente en América Latina pueden verse como momentos de un proceso de asignación de soberanías. El Estado de bienestar constituiría en esta perspectiva una división del trabajo del soberano. El derecho a recaudar una parte del producto social y el derecho a ser servido para unos y el de atender la sobrevivencia de los súbditos a otros. En el Perú de hoy esa división se presenta de manera extrema. El Presidente de la República tiene un poder mayor sobre el Ministerio de la Presidencia que sobre el Ministerio de Economía y Finanzas. El Ministerio de la Presidencia es su coto más propio.

En el mundo capitalista en general, durante este siglo ambas, estatización y privatización no han sido sino procesos marginales dentro de un orden jurídico que el artículo de Cohen presenta bien y que se basa en una amplísima proporción de propiedad privada sobre los medios de producción. Lo esencial al orden vigente es anterior y no es alterado sustancialmente por la ofensiva neoliberal. Era la presencia de los países socialistas y el propio subdesarrollo de las empresas privadas de los países pobres la que posibilitaba una proporción de propiedad estatal mayor a la usual, como se registró en el caso del Perú. 
En realidad, no es necesario que las empresas recurran a la amenaza de salida, basta que reduzcan el ritmo de inversión para que el poder derivado de la propiedad privada se exprese y coloque a los gobiernos es situación de subordinación. De hecho, hoy las grandes empresas negocian más que los tributos particulares aplicables a ellas, los sistemas tributarios mismos y la filosofía tras ellos. ${ }^{19}$ Los altos ejecutivos de las empresas grandes son y tienen que ser eminentemente políticos.

\section{f. Soberanía sin responsabilidad}

Uno de los problemas más graves de esta privatización de la soberanía política es que lo trasladado del Estado al privado es el beneficio pero no la responsabilidad social que conlleva. Sigamos una vez más a Cohen al respecto: "La mayor dificultad ... con el gobierno industrial y financiero es que los gobernantes han sido liberados de toda responsabilidad por el efecto de sus políticas sobre los seres humanos. Antiguamente, el empleador podía cumplir y tenía un interés en la salud y costumbres (morals) de sus aprendices. Ahora, los propietarios o dueños de acciones han perdido todo contacto personal con todos menos unos pocos de los que trabajan para ellos. El elemento humano está totalmente subordinado al motivo de la ganancia". ${ }^{20}$

Estamos así ante una asunción de derechos de soberanía sin la contrapartida de las responsabilidades que dicha soberanía suele conllevar: cuidar de la vida de los subordinados. ${ }^{21}$

Como el instinto de supervivencia de las personas es difícil que desaparezca, las dificultades para sobrevivir serán motivo de reclamo ante quienes asumen el rol de soberano. Esa es justamente la responsabilidad que asumen los empresarios al reivindicar el derecho a excluir al Estado del ámbito de relaciones humanas que afectan directamente aspectos esenciales a la vida de las personas. La división del trabajo según la cual los privados asumen una parte creciente de los derechos

19 Véanse las expresiones del Sr. A. Hunt de la empresas Mobil-Shell en CADE 97 sobre la filosofía tributaria que le conviene al Perú.

20 Cohen, 1927, 174.

21 Ese cuidado es el que contribuyó a la generación del 'Estado de bienestar' pocos años después de que este planteamiento de Cohen se formulara. Alguien tuvo que encargarse de las responsabilidades del soberano. 
de soberanía y el Estado cumple con las responsabilidades sociales de la soberanía convierte a éstas en costo privado, en costo del soberano privatizado. Minimizar el costo de las políticas 'sociales' es, en realidad lo mismo que minimizar la pérdida de ganancias que supone compartir con el Estado el derecho a obtener una parte del producto social.

\section{El esclavo como propietario y la esclavitud como contrato}

Las relaciones contractuales son relaciones entre propietarios. El argumento de Cohen puede ser cuestionado diciendo que, en realidad, no es cierto que algunos son propietarios y otros no lo son o que tampoco que es cierto que unas propiedades son distintas de otras; que lo único cierto es que todos somos propietarios y, en cierta medida soberanos. La moderna teoría económica, para hacer evidente que la relaciones económicas son aquellas que se realizan entre propietarios analiza con particular esmero la relación propia de la esclavitud. Si en esa relación el esclavo puede ser considerado propietario, con mayor razón en el orden jurídico actual.

\section{a. Propietario sin soberanía sobre los esclavos}

¿De qué o quién es propietario el amo? La respuesta económica es: de los activos constituidos por los esclavos o de los esclavos en cuanto activos de valor económico. El amo es dueño de fuentes de renta. En cuanto tal, no es relevante el problema de soberanía sobre el esclavo que dicha propiedad conlleva. Que el esclavo no tenga alternativa de vida fuera de su esclavitud no constituye un asunto relevante para el análisis económico. El amo es idéntico para la economía que el propietario de acciones de una sociedad anónima. Ambos son dueños de activos que tienen exactamente las mismas propiedades: dan derecho a una parte del producto social.

Toda la nueva teoría de los derechos de propiedad y de los contratos parece concentrarse en esta dimensión del problema de la propiedad y de la esclavitud. Que esa propiedad lo sea de un tipo particular de habilidades de sus trabajadores no es importante. El uso o abuso sin consecuencias económicas de las cosas en propiedad o de sus portadores, los esclavos, sale de la escena y la atención recae exclusivamente 
sobre el ingreso que esa posesión puede generar. Ese activo puede venderse y comprarse según su rendimiento. Barzel (1989) insiste en que, de hecho, algunos lograron incluso comprar sus propias habilidades y usarlas para sí mismos. Huir, más bien, era robar activos. Un esclavo que se escapa no rompe ninguna relación de subordinación, simplemente le quita un activo (las habilidades del propio escapado) al amo. Quien tiene éxito en su fuga es un ladrón, no un ser libre. Sin embargo, la teoría económica se traiciona de inmediato introduciendo el problema de la soberanía.

\section{b. El soberano supervisa}

La introducción de la relación de soberanía ocurre en el momento en el que se toma en cuenta la actividad supervisora. Después de todo, ¿quién tiene derecho a supervisar el servicio del trabajador sino quien es servido? La preocupación fundamental de la teoría económica de los contratos es que generalmente la propietaria no logra obtener todo el ingreso al que dicha propiedad da derecho. ${ }^{22}$ No lo logra porque no resulta económico supervisar la actividad hasta el punto de evitar toda sustracción del producto o toda reducción del esfuerzo laboral. Como el costo de la supervisión se considera que aumenta conforme se hace más intensiva y como, por el contrario, el producto adicional obtenido disminuye cuando se prolonga el esfuerzo en algún momento, el costo de afinar la supervisión pasa a ser superior al beneficio que se obtendría como consecuencia de dicho afinamiento. La supervisión tiene, pues, un límite económico que es distinto del límite técnico que resulta de, por ejemplo, los equipos necesarios.

\section{c. El esclavo también es propietario}

Volvemos así al inicio del intento teórico de presentar las relaciones de propiedad como totalmente distintas a las propias de la soberanía. Lo

22 En Barzell (1989) y otros autores se formula el problema en términos de contribución o aporte al proceso productivo. Sin embargo, el hecho que una propiedad de derecho a algo es, como indicó Adam Smith, totalmente distinto que contribuir a la generación de ese algo. La economía trata siempre de justificar un derecho con una supuesta contribución al producto. De ese modo, el dueño de una acción contribuye del mismo modo que un técnico 
que el esclavo puede apropiarse para sí es justamente el aumento del producto que no logra ser supervisado, o el eventual resultado del tiempo y la energía que se ahorra en el margen no supervisado de su actividad laboral. El esclavo tiene así los recursos propios que provienen de sus márgenes de libertad y que puede utilizar o no en su propio beneficio.

En cuanto la supervisión no se ejerce por razones económicas, la soberanía tampoco. A partir de un cierto momento al amo no le conviene exigir un servicio del esclavo y éste es libre. En ese margen el esclavo es considerado propietario y, en cuanto tal, participante libre de una relación contractual que involucra el intercambio de los productos que el esclavo puede producir en los márgenes no supervisados y de los que es, de hecho, aunque no lo sea de derecho, propietario.

El análisis económico se pone en evidencia cuando tiene que colocar el ámbito de la libertad y de la ausencia de soberanía en el margen del proceso económico y no en lo que constituye su corazón. Falla, pues, el intento de excluir las relaciones de autoridad-obediencia entre empleador y empleado.

\section{El lugar del contrato y de la ley}

El cambio del Estado que se propone hoy en muchos países del mundo cambia también el significado de la ley y con ella la relación entre política y mercado; entre, por un lado, el derecho del Estado a intervenir para ampliar el ejercicio efectivo de la libertad de las personas ${ }^{23}$ $y$, por otro, el derecho de las personas a la libertad respecto del Estado que le provee la ley. ${ }^{24} \mathrm{La}$ intervención puede presentarse en base a la distinción entre contrato y ley.

Tradicionalmente, el contrato debía aplicar la ley; una ley que expresaba el interés común al que tenían que adecuarse los acuerdos entre privados $^{25}$. Así, la política ponía, hasta un punto importante, los cau-

o administrador a la generación de un producto. Estamos ante el rezago ya superado de la fundamentación del derecho a una cosa por medio del trabajo.

23 Es lo que en tiempos recientes se denominan las libertades y derechos positivos siguiendo el clásico trabajo de Isaiah Berlin, recientemente fallecido.

24 Esta libertad es la que se denomina libertad negativa.

25 Zamagni, 1995, 30-1. 
ces al curso de acción económica de los privados. Esta época era, sobre todo en Europa, la del "Estado de bienestar". Ese Estado colocaba el "interés público" en un nivel más alto que en el pasado liberal. "Crecientemente, más y más norteamericanos viven de la generosidad del gobierno - asignada por el gobierno en sus propios términos y otorgada a destinatarios sujetos a condiciones que expresan el 'interés público'"26 y lo hacía porque el interés privado afectaba gravemente la vida de muchos individuos. El neo-liberalismo intenta revertir ese orden jerárquico en toda la medida de lo posible y con el viento a favor de la debacle socialista y colocar nuevamente a la economía al comando del orden vigente. "The public interest state ... represents in one sense the triumph of society over private property" decía Reich en $1964 .{ }^{27}$ Es lo que se pretende cambiar hoy.

Hoy, en efecto, la expansión del individualismo arrincona al interés común y cambia, en algunos casos hasta invertirse, el lugar de la ley y del contrato. El contrato deviene así en fuente de derecho y toma el lugar de la ley. De ese modo, el privado se protege del interés general propio de la colectividad en su conjunto. El derecho pasa de proteger el interés general a proteger el vínculo establecido voluntariamente entre los privados. El contrato adquiere cada vez más una 'función legislativa'. ${ }^{28}$ En ese sentido, un acuerdo voluntario resulta en algo más que una obligación entre las partes, también es un creador de derechos. ${ }^{29}$ Esta manera de operar es especialmente notoria en el campo de los arbitrajes internacionales debido a que no hay leyes mundiales que los regulen y un país no puede, en principio, imponer a otro sus leyes. Sin embargo en nuestros países se está extendiendo este procedimiento. ${ }^{30}$

$\mathrm{El}$ argumento económico dominante hoy en favor de un proceder basado en el arbitraje es el de la reducción de costos de transacción pero en el fondo hay uno más importante: la autonomía del particular respecto del interés común. Estamos así ante la creación de nuevas informalidades por falta de ley o por la conveniencia económica de

26 Reich, 1978, 179.

27 Reich, 1978, 180.

28 Zamagni, 1995, 31.

29 Zamagni, 1994, 126.

30 Véanse las incoherencias en la elaboración legislativa que resultan de este proceso en Bernales (1996, 319-20). 
evitar el cauce del derecho sin que ello quiera decir que se va contra el texto de la ley. La demora de los procesos judiciales, la corrupción y todo aquello que aumente los 'costos de transacción' aboga a favor de la informalización crecientemente legitimada bajo la forma de arbitrajes como medio de resolución de problemas. ${ }^{31}$ El neoliberal tiene sentimientos encontrados respecto de la idoneidad de la justicia pues la corrupción y la traba burocrática es una buena excusa para marginar al Estado de los asuntos privados. La formalización de la informalidad va de la mano con la informalización de la formalidad.

\section{c. La fuerza moral del contrato}

El contrato constituye una vía atractiva para mirar las relaciones entre personas porque se supone que el acuerdo al que se llega es voluntario y, por lo tanto, bueno para las partes. Un primer nivel de crítica que relativiza esta libertad es el que pone en cuestión la real libertad de las partes. Si bien en muchos contratos se puede hablar de una libertad apreciable, en todos aquellos en los que alguna de las partes no tiene otras opciones abiertas y la alternativa de no contratar afecta de manera significativa su vida o la de sus familiares resulta difícil hablar de libertad. En el análisis de la propiedad hemos mostrado antes que hay soberanía de por medio y, por lo tanto, problemas de libertad. Hoy, esa soberanía se sigue expresando desde en las relaciones laborales dentro de la chacra o de la casa hasta en los procesos clientelistas de apoyo social en los que la entrega de cosas es acompañada de participación en desfiles cívicos. Cuando la alternativa es sujeción o desamparo mortal es difícil tomar la naturaleza voluntaria de la aceptación de sujeción como expresión de libertad. La base moral de una sociedad contractualista no es tanta como se pretende.

Mas allá de esta importante crítica basada en la condicionalidad existente en mayor o menor medida en cada contrato se encuentra el cuestionamiento a la profundidad moral de las relaciones contractuales. En la visión contractualista no importa, en realidad, qué es lo bueno; es el procedimiento el que resulta relevante. En dicha perspectiva, una

31 A la vez, estamos ante una nueva manera de afirmar el rol de la sociedad civil ante el Estado; de relativizar su importancia en el momento de reducir o resolver los conflictos entre personas. 
sociedad justa no incluye una visión específica de lo bueno y lo malo. ${ }^{32}$ Para Rawls, por ejemplo, se llega a la justicia por medio de un procedimiento contractual. La crítica de Zamagni a este clásico de la teoría de la justicia es interesante y la resumimos para motivar nuevas reflexiones.

Para este autor, en el planteamiento de Rawls "la sociedad justa debería basarse en principios que no implican una visión específica de lo que es bueno". ${ }^{33}$ Así, el concepto de justicia de Rawls "puede liberar lo que es justo del tutelaje de lo que es bueno". ${ }^{34}$ Pero lo bueno, dice el crítico, sigue siendo importante porque es lo que "inspira las acciones humanas ofreciéndole al hombre una buena causa hacia la cual fuera valioso dedicar la vida sin lamentarse." 35 Después de todo, "el acuerdo entre las partes resulta per se una caja vacía que puede ser llenada con contenido buenos o malos." ${ }^{6}$

Finalmente, sigue Zamagni, la visión contractualista estrecha la visión de las relaciones humanas. Muchas de ellas no encajan en el modelo contractualista de relación que dicha visión propone. Tal es el caso de las relaciones puramente conflictivas como son las relativas a la justicia o las relaciones de coordinación. Una teoría moral que pretende ser general no puede restringirse a ciertos tipos de relación. En general, la autoridad moral de la sociedad basada en contratos tiene varias debilidades importantes, sin que ello le quite un rango de aplicabilidad apreciable.

\section{Conclusión}

La creciente presencia del contrato en las relaciones humanas equivale a la privatización de las relaciones de poder entre las personas, a la marginación del Estado en la regulación de esas relaciones. Esa marginación se expresa en muchos campos siendo uno de los más importantes el laboral. La necesidad de corregir esta situación no es

32 Zamagni, 1994, 125.

33 Zamagni, ibid.

34 Zamagni, 1994, 126.

35 Zamagni, ibid.

36 Zamagni, 1994, 127. 
una novedad y es parte de un proyecto civilizatorio que surge durante el periodo de expansión original del orden capitalista. Como dice Cohen: "La subordinación de todo al único objetivo de la ganancia monetaria lleva al gobierno industrial a adquirir la forma de una monarquía absoluta. La monarquía tiene cierta simplicidad y conveniencia; pero a largo plazo es rara vez lo mejor para todos los concernidos. Tarde o temprano lleva a la insurrección. Es miope asumir que un empleador no puede manejar su negocio sin el derecho absoluto a contratar y despedir cuando le de en gana. Es interesante anotar que incluso un ejército moderno es manejado sin que el general tenga el derecho absoluto de contratar y despedir. El Sha de Persia quedó anonadado cuando un embajador británico, Sir John Malcolm, le informó que el Rey de Inglaterra no podía decapitar a ninguno de sus cortesanos a su antojo. Pero Sir John Malcolm estaba igualmente sorprendido al observar las elaboradas precauciones que el Sha tenía que tomar para impedir que lo asesinen. ¿ No será que un gobierno constitucional democrático o limitado en la industria tiene ciertas ventajas humanas sobre la monarquía ilimitada?" 37

Obviamente, no se trata simplemente de trasladar esquemas de gobierno de una esfera a otra de la vida, pero la larga cita anterior pone de relieve varias de nuestras preocupaciones actuales ante el fundamentalismo con el que se pretende separar economía de política, se posterga y se degrada la asunción de la responsabilidad pública y se impulsa la institucionalización de un orden dual en el campo de los derechos humanos en sentido amplio. Quizá no sea una monarquía absoluta la que, paradójicamente, pretendan instaurar los neoliberales más convencidos pero ciertamente es necesario considerar que el Perú no parece dispuesto a retornar a un régimen de sujeción personal que recuerde la servidumbre de la que se han escapado tantos campesinos y tantas empleadas domésticas. Está por verse si es que los instintos más profundos de los neoliberales son liberales. A pesar de los esfuerzos de De Soto por mostrar que la función empresarial estaba siendo asumida por los sectores sociales emergentes $y$, ahora por asegurar jurídicamente los derechos de propiedad, no podemos evitar la impresión de que la expansión del ámbito de la propiedad y del contrato en el mer-

37 Cohen, $1927,174$. 
cado también está trayendo consigo la revigorización de costumbres importantes del viejo orden jerárquico peruano; costumbres que la propia informalidad estaba reduciendo. Esto se revela en que el paso de seńores a ciudadanos en el campo político no siempre corresponde con el abandono total del status de señores y en una crisis económica e institucional como la actual, la servidumbre en el comportamiento laboral se convierte muchas veces en la condición obligada para mantener el empleo y llevar algo a la casa. ${ }^{38}$

Las reformas laborales no son simplemente cuestión de nivel salarial; también lo son de status, de efectiva libertad ciudadana. La flexibilización laboral es un cambio en la naturaleza del contrato que añade sujeción para unos y reduce responsabilidad soberana para otros. Nuestro objetivo ha sido llamar la atención sobre el componente de sujeción personal y nacional que trae consigo la afirmación casi exclusiva de la propiedad privada en terrenos en los que no es conveniente disminuir la acción de la ley y del interés común y donde el mero hecho de tener un status de ciudadano no es garantía de trato horizontal y de pleno despliegue de la personalidad, creatividad y voluntad de aporte que necesitamos en el país.

\section{Referencias bibliográficas}

Bernales, Entique

1996 La Constitución de 1993. Análisis comparado. Lima: Konrad Adenauer-CIEDLA.

BARZEL, Yoram

Economic Analysis of Property Rights. Cambridge: Cambridge University Press.

CoHen, Morris

1933,1927 Law and the Social Order. New York: Harcourt, Brace and

38 Véase al respecto los planteamientos en Cuestión de Estado de Sinesio López sobre el paso de siervos a ciudadanos en el Perú del siglo XX, las inquietudes de Catalina Romero respecto de la necesidad de incorporar al análisis el paso de señores a ciudadanos y la experiencia testimonial de Francisco Miró Quesada sobre este último punto. 
Company. Las referencias son tomadas de una reproducción editada por Macpherson (1978).

Cortina, Adela

1994 Ética de la empresa. Madrid: Trota.

IGUíNIIZ, Javier

1993 "Constitución y derecho a la vida". Páginas. No. 120. Lima: mayo de 1993.

LÓPEZ, Sinesio

1997 "El itinerario de la ciudadanía". Cuestión de Estado. Revista del Instituto de Diálogo y Propuesta (IDS). No. 20, Lima: abril.

MaCpHERSON, C.B. de.

1978 Property. Mainstream and Critical Positions. Toronto: University of Toronto Press.

Miró Quesada, Francisco

(1997) “De señores a ciudadanos". Cuestión de Estado. No. 20, Lima: IDS, abril.

Piore, Michael J.

1995 Beyond Individualism. Cambridge: Harvard University Press.

ReICH, Charles A.

1978 "The New Property". En: Macpherson, op.cit.. Extracto de artículo en Yale Law Journal, 73, 1964.

Romero, Catalina

1997 "La ciudadanía es siempre una tarea inacabada". Cuestión de Estado. No. 20, Lima: IDS, abril.

SMITH, Adam

1958 Investigación sobre la naturaleza y causa de la riqueza de las naciones. México: Fondo de Cultura Económica. 
ZaMAGNi, Stefano

1994 "Efficiency, Justice, Freedom or the Relationship between Market, Stat and Civil Society" Estratto da "Alma Mater Studiorum" 1994, VII, 1. Università degli studi di Bologna

ZAMAGNI, Stefano

1995 "La globalizzazione come specificità dell'economia postindustriale: implicazioni economiche e opzioni etiche". En: Zamagni, Stefano (ed..) Globalizzare l'economia. San Domenico di Fiesole: Edizioni Cultura della Pace (ECP).

WALRAS, León

1978 Elementos de economía política pura (o teoría de la riqueza social). Madrid: Alianza 